\title{
WHEN EXPERTS BECOME LIABILITIES: DOMAIN EXPERTS ON BOARDS AND ORGANIZATIONAL FAILURE
}

\author{
JUAN ALMANDOZ \\ IESE Business School \\ ANDRÁS TILCSIK \\ University of Toronto
}

\begin{abstract}
How does the presence of domain experts on a corporate board-directors whose primary professional experience is within the focal firm's industry-affect organizational outcomes? We argue that under conditions of significant decision uncertainty, a higher proportion of domain experts on a board may detract from effective decision making and thus increase the probability of organizational failure. Building on exploratory interviews with board members and CEOs, we derive hypotheses from this argument in the context of local banks in the United States. We predict that the greater the level of decision uncertainty-due to rapid asset growth or operation in less predictable markets-the stronger the relationship between the proportion of banking expert directors and the probability of bank failure. Longitudinal analyses of 1,307 banks between 1996 and 2012 support this prediction, even after accounting for both the overall level of professional diversity among directors and banks' different propensities to have an expert-heavy board. We discuss implications for the key dimensions of board composition, the conditions under which the professional background of directors is more or less consequential, and the mechanisms whereby board composition affects organizational outcomes.
\end{abstract}

The board of directors is a major part of a firm's governance structure (Baysinger \& Butler, 1985) and a crucial strategic decision-making group (Forbes \& Milliken, 1999). Given the importance of boards, the question of how board composition affects corporate performance and survival has been an enduring concern for organizations (PricewaterhouseCoopers, 2014) and organizational scholars (Baker \& Powell,

Authors are listed in alphabetical order and contributed equally. We thank Associate Editor Martine Haas and three anonymous reviewers for their thoughtful guidance and extraordinary dedication throughout the review process. We are greatly indebted to Christopher Marquis for his early comments and support for this research. We thank Anne Bowers, Frank Dobbin, Chris Liu, Anette Mikes, Royston Greenwood, Sameer Srivastava, Pat Thornton, and participants at the Inaugural Paul R. Lawrence Conference at Harvard Business School for helpful suggestions. We are grateful to all the bank CEOs and board members who were interviewed as part of this research, and to Chris Clearfield, Sangwami Mabhena, and Ricard Alemany, who provided helpful practitioner input. We thank Andreu Peiró, Ferrán Casas, Francisco Pareja, and Michael Cheely for excellent research assistance. This paper was made possible through a research grant from IESE Business School.
2009; Dalton \& Dalton, 2011; McNulty, 2013; Stiles, 2013) alike. Existing research in this area has examined how the professional backgrounds and company affiliations of directors influence a firm's financial performance (Fogel \& Geier, 2007; Pearce \& Zahra, 1992; Pfeffer, 1972, 1973; Rosenstein \& Wyatt, 1990) and ability to avoid bankruptcy (Chaganti, Mahajan, \& Sharma, 1985; Daily \& Dalton, 1994; Platt \& Platt, 2012), though this large amount of literature has uncovered few consistent and unequivocal links between board composition and a firm's financial health (Dalton, Daily, Ellstrand, \& Johnson, 1998; Dalton \& Dalton, 2011).

Research in related areas points to the possibility that an important but largely overlooked aspect of board composition may be the proportion of domain experts on a board, that is, the proportion of those directors whose primary professional experience is within the focal firm's industry and who are thus seen as possessing a high degree of competence in that domain (Evetts, Mieg, \& Felt, 2006; Furr, Cavarretta, \& Garg, 2012; Gerver \& Bensman, 1954; Mieg, 2006). Recent research suggests that the proportion of domain experts in a strategic decision-making group can significantly shape 
a firm's strategic direction and its responses to the environment (Furr et al., 2012), which other research in turn has shown to be key determinants of organizational survival chances (Dencker, Gruber, \& Shah, 2009; Haveman, 1992). This potential link between the presence of domain experts in strategic decision-making groups, such as corporate boards (Forbes \& Milliken, 1999), and organizational survival is important to understand not only because ensuring survival is a critical concern for organizations (Hambrick \& D’Aveni, 1992; Mellahi \& Wilkinson, 2004) but also because the proportion of domain experts is a readily observable dimension of board composition that organizations can directly influence when creating a board or selecting new directors (see Almandoz, 2012; Pfeffer, 1972).

Exploring how the presence of domain experts on boards might affect organizational survival is all the more important because the nature of this relationship is not obvious. Though a corporate board is likely to benefit from domain experts' collective knowledge of the focal industry (see Almandoz, 2012), research suggests that decision-making groups dominated by domain experts might also exhibit several harmful tendencies-such as cognitive entrenchment (Dane, 2010; Furr et al., 2012), overconfidence (Lin \& Bier, 2008; Sniezek \& Henry, 1989), and limited task conflict (Amason, 1996; Jehn, 1995)—that can detract from effective decision making and thus contribute to the risk of organizational failure (see Forbes \& Milliken, 1999; Mellahi \& Wilkinson, 2004). Given these conflicting possibilities, this study seeks to explore the relationship between the proportion of domain expert directors on a corporate board and the likelihood of organizational failure.

To date, research on the professional composition of boards and other strategic decision-making groups has traditionally focused on diversity in group members' professional backgrounds (Bunderson \& Sutcliffe, 2002; Milliken \& Martins, 1996; Van Knippenberg \& Schippers, 2007; Westphal \& Milton, 2000; Williams \& O'Reilly, 1998). The degree of professional diversity, however, is conceptually distinct from the proportion of domain experts. To illustrate, consider two simple examples. First, a manufacturer of solar panels has a board of directors that includes five solar energy experts, two lawyers, and two bankers. Second, the board of another firm in the same industry includes two solar energy experts, five lawyers, and two bankers. Thus, both boards include nine directors from three occupational categories such that the largest category includes five directors, while the other two categories include two directors each. In the literature on team diversity, these two boards would be typically coded as equally diverse in terms of the variety of professional backgrounds (see Harrison \& Klein, 2007). Yet these boards differ dramatically in the proportion of domain expert directors. While the majority (56\%) of the first board is composed of solar industry experts, such directors are a minority $(22 \%)$ in the second board. Studies on board and executive team diversity, however, do not directly distinguish experts from non-experts within a given domain and hence cannot answer the question of how the proportion of domain experts affects a firm's chances of survival or failure.

To address this question, we build on prior research on domain experts and decision-making groups (Forbes \& Milliken, 1999; Furr et al., 2012) to develop the argument that the relationship between the proportion of domain experts on a board and the risk of organizational failure is contingent on the level of decision uncertainty (Elbanna \& Child, 2007). We suggest that when decision uncertainty is greater, the potential negative characteristics of domain expert-heavy boards-cognitive entrenchment, overconfidence, and limited task conflictare more likely to be influential and undermine effective strategic decision making. Thus, in the presence of greater decision uncertainty, there is likely to be a stronger relationship between the proportion of domain expert directors and the risk of organizational failure.

We elaborate and test this argument in the context of the U.S. banking sector, focusing on the board composition and survival chances of new and recently established local banks between 1996 and 2012. Local banks, or community banks, have their own legal charter, total assets below $\$ 1$ billion, and a business model focusing on the county or counties where their headquarters is located. This is an opportune research setting for three reasons. First, a local bank's board is an active strategic decision-making group rather than simply an oversight body (Almandoz, 2012). Second, given the liability of newness (Stinchcombe, 1965), a focus on young banks allows us to observe a population in which failure is likely to be a fairly common occurrence rather than a rare event. Third, there is substantial variation in this context in both the proportion of domain experts on boards (i.e., directors from a banking background versus those with a background in law, insurance, medicine, the public sector, or the military, etc.) and several conditions associated with decision uncertainty: (1) rapid asset growth, (2) 
involvement in non-standard real estate lending, or (3) operation in a local area with many direct competitors.

We hypothesize that the greater the degree to which these conditions are present, the stronger the relationship between the proportion of domain expert directors and bank mortality. Using a longitudinal dataset and a two-stage estimation technique that corrects for differences in banks' propensity to have an expert-heavy board, we generally find support for this prediction. This result is robust to controlling for the level of professional diversity on the board. Thus, we find that in the presence of significant decision uncertainty, the higher the proportion of domain experts on a board, the higher the likelihood of organizational failure. At the same time, there is no evidence that a higher proportion of banking experts leads to higher returns.

Our study has several implications for organizational scholarship on corporate boards. At the most basic level, this research provides cause to rethink assumptions about what the key dimensions of board composition are. As we show, the proportion of domain experts is a highly consequential yet previously neglected board characteristic that can affect an outcome of central importance to organizations: whether they survive or fail. Although domain experts are often assumed to be highly skilled actors who can effectively manage domain-specific risks (see Almandoz, 2012; Shapira, 1995), we show that-under certain conditions-a high proportion of domain experts may actually hurt the survival chances of an organization. Our contingency perspective delineates the boundaries of this hypothesis and highlights the theoretical importance of decision uncertainty for influencing the extent to which board composition matters for organizational outcomes. Thus, this perspective contributes to our understanding of board composition by identifying conditions under which the professional makeup of boards is more or less consequential. In doing so, this study also sheds new light on mechanisms whereby board composition can affect strategic decision making and, ultimately, the fate of an organization.

\section{DOMAIN EXPERTS, BOARDS, AND ORGANIZATIONAL FAILURE}

Intuitively, one might expect a positive relationship between the proportion of domain expert directors and corporate survival. A critical function of boards is to make strategic decisions (Forbes \& Milliken, 1999; Lynall, Golden, \& Hillman, 2003; Westphal, 1999), and a higher proportion of domain experts may foster more effective decision making as a result of board members' more extensive collective knowledge of risks and opportunities in the focal industry (see Furr et al., 2012). Effective strategic decisions, in turn, are key to avoiding corporate failure (Daily \& Dalton, 1994; Porter, 1991). Moreover, boards comprised of higher proportions of domain experts may also command greater respect and recognition in the focal industry and confer a higher degree of legitimacy on the firm (Daily \& Schwenk, 1996; Lynall et al., 2003), thus increasing the chances of organizational survival (DiMaggio \& Powell, 1983; Meyer \& Rowan, 1977; Ruef \& Scott, 1998). At the same time, existing scholarship suggests several mechanisms by which a higher proportion of domain expert directors might make a board less effective as a strategic decisionmaking group: cognitive entrenchment, group overconfidence, and reduced task conflict. We discuss each of these mechanisms below, both in general and in the specific context of local banks. In doing this, we build on prior research on domain experts and decision-making groups as well as exploratory interviews (described in Appendix A) that we conducted with board members and CEOs of local banks.

\section{Cognitive Entrenchment}

Recent research suggests that strategic decisionmaking groups with a greater proportion of domain experts are less likely to "recognize, interpret, and integrate new information and alter their perspectives" as the environment changes (Furr et al., 2012: 238). In the context of the solar energy industry, for example, management teams in which the majority of executives were domain experts were less flexible than other teams in implementing technological changes to respond to environmental shifts (Furr et al., 2012). Consistent with this finding, scholars have highlighted a tendency of individual domain experts for cognitive entrenchment, that is, a high degree of stability in their domain schemas (Dane, 2010). Thus, if domain experts dominate the collective framing and discussion of problems and opportunities in a strategic decision-making group (Kaplan, 2008), this tendency for cognitive entrenchment can make it more difficult for the group to recognize and flexibly react to new information (Furr et al., 2012).

Consistent with these ideas, our interviews in the context of local banks suggest that directors with a banking background might bring with them entrenched perspectives and habits, which they then attempt to "replicate" on the board. This, in turn, is more likely to influence a board's decisions if a larger 
number of bankers are present in the group. In contrast, boards with fewer directors who have previous banking experience might be less vulnerable to this problem. As one CEO explained:

[With regard to] banking experience, it could be that [bankers] brought with them habits from the other institutions and perhaps those habits were not always good. They brought those to the table and replicated that. Whereas our culture was drawn from within because we have a limited amount of banking experience, you know, on the board, only $25 \%$ of the board has previous banking experience. I don't think we brought any baggage with us.

The cognitive "baggage" that bankers brought to boards surfaced in several interviews. As another CEO put it, "Bankers tend to use models, let's face it. They run models and they run numbers: What is your debt coverage? What is your debt to income? The truth of the matter is sometimes just a bit of local knowledge gives you a better feeling of the risk factors associated with the loan." Another respondent explained: "The benefits of not having prior bankers is that there is no baggage to speak of in terms of, "With this [previous] bank, we did it this way." Consistent with these accounts, other informants emphasized that having a higher proportion of non-expert directors enables boards to consider the ideas of domain experts more critically and thus prevent the replication of entrenched decision patterns. On such boards, as one director put it, "What could happen is that I am a banker and if I have given loans to [a certain type of borrower] in the past, I am going to tend to give loans to [those borrowers] again. Whereas somebody with fresh eyes [i.e., not a banker] coming to look at it may say: Wait a minute!"

\section{Group Overconfidence}

A greater proportion of domain experts on a board may also be associated with a higher level of group overconfidence. Overconfidence is a tendency to overestimate the accuracy and precision of one's judgments and predictions, that is, to assume overly narrow confidence intervals around one's estimates of unknown values and probabilities (Alpert \& Raiffa, 1982; Brenner, Koehler, Liberman, \& Tversky, 1996; Fellner \& Krügel, 2010; Fischhoff, Slovic, \& Lichtenstein, 1977; Glaser, Langer, \& Weber, 2013). As we define it, overconfidence has also been termed "overprecision" in the literature (Moore \& Healy, 2008). Group overconfidence refers to the same tendency at the level of a decision-making group: an inflated sense of confidence in the precision and accuracy of group judgments and forecasts (Wang \& Thompson, 2006; see also Sniezek \& Henry, 1989).

At the individual level, scholars have noted a potential tendency of domain experts for overconfidence in the accuracy of their professional judgments and predictions (Cooke, 1991; Shlyakhter, Kammen, Broido, \& Wilson, 1994). In fact, overconfidence has been described as "one of the most common (and potentially severe) problems in expert judgment" (Lin \& Bier, 2008: 711), and "manifestations of systematic overconfidence have been found...among physicists, doctors, psychologists, CIA analysts, and others making expert judgments" (Angner, 2006: 3; see Christensen-Szalanski \& Bushyhead, 1981; Henrion \& Fischhoff, 1986; Oskamp, 1982).

At the group level, the overconfidence of domain experts who have similar assessments of a situation because of shared domain schemas can substantially affect group decisions especially because of the high degree of status and authority granted to experts in decision-making bodies (see Derber, Schwartz, \& Magrass, 1990; Freidson, 2001; Zald \& Lounsbury, 2010). Moreover, group polarization (Friedkin, 1999; Isenberg, 1986) can further increase the effect of overconfidence in decision-making groups with higher proportions of experts. In the context of corporate boards, group polarization implies that board decisions will reflect the amplification of directors' average initial positions (Zhu, 2013). Thus, if domain experts have similar assessments of a situation because of shared domain schemas and overconfidence about the accuracy of their assessments, then group polarization in an expert-heavy board can amplify, beyond the directors' average tendency, the board's inclination toward domain experts' overconfident assessments. Overconfidence, in turn, can undermine effective strategic decision making because it may foster a less accurate assessment of risks and an overly optimistic estimate of the probability of success of a given action (Angner, 2006; Russo \& Schoemaker, 1992).

Consistent with these ideas, our interviews suggest that local bank directors who are banking experts are often highly confident that their understanding of market trends and risks is accurate. Numerous directors who had a background in banking emphasized that for them, because of their experience in the banking domain, "almost every deal is doable." As one banker boasted, sometimes "the market is not willing [to provide a loan], but you do because you know better." Several CEOs and directors from other backgrounds have noted that this tendency is more 
visible in boards with a higher proportion of bankers. As one director summarized:

If I got a board, which has got a lot of bankers on it, they are going to tend to reach for loans a little bit more because they believe that they have got a little bit more background and experience. Whereas, you know, other people who aren't bankers tend to be a little more cautious.

Several informants echoed the notion that directors with expertise in other domains might be more cautious and critical when making strategic decisions. As a director with a background in law noted, non-banker directors "often play the role of devil's advocate, taking the situation to its worst conclusion." Thus, boards with a higher proportion of such directors may be more likely to respond to strategic proposals with a skeptical "demand [for] more reporting and analytics... [and say], 'No, we are not going to do that. We are not going to make a decision today because you didn't give us enough information to make the decision."”

\section{Limited Task Conflict}

A higher proportion of domain experts might also reduce the level of task conflict on a board. Task conflict, or cognitive conflict, involves "disagreements about the content of the tasks being performed, including differences in viewpoints, ideas and opinions" (Jehn, 1995: 258). In corporate boards and other strategic decision-making groups, some level of task conflict is critical for effective decision making because task conflict results in "critical and investigative interaction processes" (Amason, 1996: 104) and "the consideration of more alternatives and the more careful evaluation of alternatives," which "contribute to the quality of strategic decision making in uncertain environments" (Forbes \& Milliken, 1999: 494). A higher proportion of domain experts on a board, however, might make non-expert directors less willing or less able to challenge experts to justify their assumptions and to consider alternative courses of action (Woolley, Gerbasi, Chabris, Kosslyn, \& Hackman, 2008).

Of course, a reduced level of task conflict might also be expected whenever a board has a high proportion of directors from one single profession even if that profession is not identified with the focal domain. But, given the high level of status that domain experts enjoy in decision-making groups (Freidson, 1986; Meyer \& Rowan, 1977; Ungar, 2008), a high proportion of domain experts is especially likely to reduce task conflict. As Woolley and her colleagues (2008: 354) noted, "high-status experts may be disinclined to take seriously the views of [non-expert] others," who in turn might be tempted to give more credence to experts in their decision-making group than is warranted. As a result, a higher proportion of domain expert directors may limit task conflict, which can undermine the careful deliberation of different perspectives and thus contribute to less well-considered strategic decisions (Amason, 1996; Forbes \& Milliken, 1999).

Likewise, our interviews suggest that the level of task conflict tends to be lower when the proportion of banking experts on a local bank's board is higher. Several informants noted that banking experts on boards enjoyed a high level of deference and even a "prima donna" status, which made it more difficult for non-experts to express doubts or raise critical questions in boards with higher proportions of bankers. This suggests that a heavier presence of domain experts on a board is more likely to suppress cautionary voices of dissent. The CEO of a bank with only a few banking experts explained:

[In a board with more banking experts] there could also be some egos involved that, you know-here is the way I have done it all my life and that's the way we are going to do it. And everybody respects each other's ego at that table and at the end of the day, they won't really call each other out. Whereas here, when we see something we don't like, no one is afraid to bring it up because we are not stepping on anybody's toes because of their massive banking experience in the past.

Overall, both existing research and our interviews suggest three mechanisms whereby the proportion of domain experts may be negatively related to the effectiveness of a board as a strategic decisionmaking group: cognitive entrenchment, group overconfidence, and reduced task conflict. These mechanisms, in part, reflect tendencies in expert cognition-how domain experts tend to interpret the environment and judge the accuracy of their assumptions about it-but, at the board level, these mechanisms are likely to manifest themselves in large part because of the status of domain experts (Derber et al., 1990). Thus, the proportion of domain experts is likely to affect boards not simply because of a mere aggregation of domain experts' individuallevel tendencies but because other board members tend to defer to domain experts in the group (Woolley et al., 2008). In other words, domain experts' judgements, which might be subject to cognitive entrenchment and overconfidence, are likely to be 
problematic not simply in their own right, but rather because deference to expertise makes other board members unable or unwilling to challenge experts' judgements. In this sense, the three potential mechanisms at play are likely to operate jointly rather than independently: Lower task conflict resulting from deference to expertise can reinforce domain expert directors' overconfidence and cognitive entrenchment as the board fails to consider alternative views.

\section{The Moderating Role of Decision Uncertainty}

Although the above-described three mechanisms imply that a greater proportion of domain experts on a board may be associated with less effective decision making, these mechanisms are unlikely to be equally strong and consequential in all situations and probably do not always offset the benefits that domain experts might bring to a board. Specifically, we argue that these detrimental mechanisms are more likely to surface under greater decision uncertainty. Identified in prior work as a critical factor that affects strategic decision making, decision uncertainty is high when outcomes are difficult to predict and information about relevant cause-and-effect relationships is limited or ambiguous-such as when decision makers cannot easily anticipate the consequences of their investments or the strategic moves of competitors (Beach \& Mitchell, 1978; Dean \& Sharfman, 1993; Elbanna \& Child, 2007; Papadakis, Lioukas, \& Chambers, 1998). Decision uncertainty often arises from the environment and the activities of the focal organization (Leblebici \& Salancik, 1981). For example, decision uncertainty is likely to be greater when an organization operates in markets that are less predictable (e.g., due to intense competition or to the lack of clear and reliable information) or when it is expanding rapidly into uncharted market segments. In contrast, decision makers tend to face less uncertainty when the organization is in a relatively predictable market during a period of organizational stability (Busenitz \& Barney, 1997; Kobelsky, Hunter, \& Richardson, 2008; Leblebici \& Salancik, 1981).

Existing research suggests several reasons why tendencies for cognitive entrenchment, overconfidence, and limited task conflict may be both more pronounced on a board and more consequential for the focal organization under higher levels of decision uncertainty. First, the higher the degree of decision uncertainty, the greater the likelihood that cognitive entrenchment will undermine the effectiveness of strategic decision making. As Dane (2010: 592) noted, entrenchment "may be especially costly during periods of change and uncertainty" because such periods demand greater flexibility from decision makers to address changing, unpredictable conditions (see also Tiwana, Wang, Keil, \& Ahluwalia, 2007). In contrast, in routine situations with a relatively high degree of stability and predictability, entrenchment might be unproblematic, or even advantageous, as it can "produce functional and reliable responses to commonly encountered problems" (Dane, 2010: 592). Consistent with this idea, there is evidence that inflexibility in modifying corporate strategy and structure is more detrimental to a firm's survival chances under uncertain conditions than in more predictable and stable situations (Haveman, 1992).

Second, under increased decision uncertainty, expert overconfidence is both more likely to occur and more likely to become problematic for strategic decision making in groups. Prior research suggests that overconfidence regarding one's professional judgment is more likely "when a decision environment is nonrepetitive or ambiguous" (Simon \& Houghton, 2003: 139). For example, while meteorologists do not systematically overestimate the accuracy of their predictions when forecasting rain (Murphy \& Winkler, 1977), they do exhibit overconfidence when predicting tornadoes-that is, when they lack a sufficient number of repetitive and unambiguous prior observations to help calibrate judgment (Murphy \& Winkler, 1982). Similarly, the greater the level of market uncertainty, the higher the degree of overconfidence that financial professionals exhibit (Ben-David, Graham, \& Harvey, 2013). Moreover, expert overconfidence may be less problematic for strategic decisions when decision makers face limited uncertainty. Because predictable environments tend to be more "forgiving," the consequences of poor decisions due to overconfidence might be limited in the absence of uncertainty (Davis, Eisenhardt, \& Bingham, 2009).

Finally, the lack of task conflict among board members is also more likely to be consequential under greater decision uncertainty. Because task conflict fosters more effective and critical consideration of information and alternative courses of action (Jehn, 1995), it is particularly important to the quality of strategic decisions under uncertainty (see Forbes \& Milliken, 1999). By contrast, under more stable and predictable circumstances, and when dealing with commonly encountered problems, the critical and investigative interaction processes that result from task conflict in a board may be less essential for effective decisions (Forbes \& Milliken, 1999). 


\section{Decision Uncertainty in the Context of Local Banks}

Taken together, the above arguments suggest that the possible dysfunctional tendencies that may be related to greater proportions of domain experts on boards-cognitive entrenchment, group overconfidence, and limited task conflict-are more likely to prove harmful when decision uncertainty is higher. In the context of local banks, prior research and our interviews point to three conditions under which boards experience greater decision uncertainty.

First, our interviewees suggest that the decision makers of a local bank face significant uncertainty if the bank is experiencing rapid asset growth. In such cases, because asset growth involves new lending, the bank is likely to be operating in uncharted market territory, often facing decisions about previously unknown borrowers, lending areas, and sources of loans (Office of the Comptroller of the Currency, 2001). Consistent with this observation, finance scholars have noted that asset growth tends to create significant uncertainty for a bank's decision makers because it often implies that the bank is dealing with market segments and "borrowers... that were previously unknown or non-existent" (Foos, Norden, \& Weber, 2010: 2929). Similarly, our interviews with board members suggest that fast asset growth entails greater uncertainty because it involves rapidly expanding the pool of potential borrowers and, at the board level, having to manage the approval and oversight process for a large number of loans for such borrowers. Thus, fast asset growth is likely to be a key source of uncertainty for local banks' boards.

Second, our interviews suggest that the level of uncertainty that a local bank's decision makers face depends partly on the type of lending markets in which the bank operates. In particular, our informants have noted that a high degree of uncertainty is associated with lending markets that involve nonstandard real estate loans, that is, loans for real estate other than ordinary family residential properties. Such non-standard loans include land, construction, and development loans, farm loans, large multifamily residential loans, and other commercial real estate loans (Basel Committee on Banking Supervision, 2006). The boards of banks that are heavily involved in non-standard real estate lending markets face uncertainty because clients in such markets tend to be highly heterogeneous, often with uncommon profiles (see Achrol \& Stern, 1988). Thus, in decisions about major loans in such markets, boards have limited access to past trends, historical performance, or other systematic information that could reduce the degree of uncertainty about the associated risks and potential profits. This is in stark contrast to banks that are primarily involved in standard real estate markets focused on regular family residential properties, which are characterized by a low degree of uncertainty because of the availability of detailed information about past patterns and risk factors (see Busenitz \& Barney, 1997; Leblebici \& Salancik, 1981).

Third, the level of decision uncertainty may be greater for boards of local banks that operate in a geographic area with many other locally-based banks. Our interviewees have consistently indicated that the direct competitors of a local bank are other local banks in the same area. Local banks compete for deposits, loans, and investor capital most intensely not with large regional or national banks but with other local banks, which offer similar "relationship-based" local services. Having a large number of direct competitors, in turn, can increase environmental complexity, which makes anticipating rivals' actions difficult (see Kor, Mahoney, \& Watson, 2008), thus creating uncertainty for strategic decision makers. Thus, having a high number of locally-based competitors is a likely source of decision uncertainty for boards in our setting.

\section{Domain Expert Directors and the Risk of Bank Failure}

The juxtaposition of our arguments about the moderating role of decision uncertainty in general and the specific conditions that create decision uncertainty in the particular context of local banks suggests several hypotheses. We expect that under each of the conditions associated with decision uncertainty-(1) fast asset growth, (2) involvement in non-standard real estate lending markets, and (3) a high number of other locally-based banks in the same area-a higher proportion of domain experts on a board may contribute to less well-considered or less cautious strategic decisions and thus increase a bank's risk of failure. In other words, we hypothesize that the greater the degree to which these conditions are present, the stronger the relationship between the proportion of domain expert directors and bank mortality. Accordingly, we propose three closely related hypotheses that reflect our general argument in the banking context.

First, because critical and cautious deliberations are particularly important for effective decision making under uncertainty, the proportion of domain experts on a board will be more strongly related to the risk of failure if the focal bank is experiencing faster asset growth, a key condition associated with increased decision uncertainty for local banks. Hence we predict: 
Hypothesis 1. The higher a bank's asset growth rate, the stronger the relationship between the proportion of banking expert directors and bank mortality.

Second, by the same general argument, we suggest that the proportion of domain expert directors will be more strongly related to the risk of failure when the bank is more heavily involved in the market for nonstandard real estate loans, a lending market characterized by a high degree of uncertainty. Of course, as we have emphasized, the primary experts in this context are bankers, so our hypotheses focus on the proportion of directors with a background in banking. With regard to real estate lending, however, there is also a second group of relevant experts: directors who are experts in the real estate domain. Thus, we predict that the proportion of real estate experts will also be more strongly associated with the likelihood of failure when the focal bank is more heavily involved in non-standard real estate lending.

Hypothesis 2a. The greater a bank's involvement in non-standard real estate lending, the stronger the relationship between the proportion of banking expert directors and bank mortality.

Hypothesis $2 b$. The greater a bank's involvement in non-standard real estate lending, the stronger the relationship between the proportion of real estate expert directors and bank mortality.

Finally, as noted above, having a large number of direct competitors is another potential source of decision uncertainty for local banks' boards. Thus, a third prediction that emerges from our argument is that the strength of the relationship between the proportion of domain expert directors and the likelihood of bank failure will increase with the number of direct competitors, that is, the number of other locally-based banks in the same geographic area.

Hypothesis 3. The greater the number of locallybased banks in the focal bank's geographic area, the stronger the relationship between the proportion of banking expert directors and bank mortality.

\section{METHODS}

We tested our hypotheses using a dataset linking board members' professional biographies to the failure of local banks. To identify domain experts on boards, we obtained biographical data on directors from three sources. The first source was the regulatory form "Interagency Charter and Federal Deposit Insurance Application," a filing of prospective banks that is necessary to receive the required deposit insurance guarantee from the Federal Deposit Insurance Corporation (FDIC) and to receive federal or state charter approval from such regulators as the Federal Reserve, the Office of the Comptroller of the Currency, or state-level regulators. The second source was the "Annual Report of Bank Holding Companies" form, which includes information about the bank subsidiaries of holding companies. Both these forms include biographical statements of board members at the time of founding, describing their prior professional experiences and other relevant qualifications. The third source of biographical data was SNL Financial, a research organization providing news and data about U.S. banks. Through SNL Financial, we obtained biographical information on directors who joined a relevant board after the founding stage. We gleaned these data from banks' press releases and documents that banks issued to regulators at any point after their founding.

\section{Sample}

We studied local banks founded between 1996 and 2012. Consistent with the FDIC's definition, we define a local bank, or community bank, as a bank that has: (a) its own legal charter, (b) aggregate assets below $\$ 1$ billion, and (c) a business model that focuses on lending and deposit gathering activities in a county (or adjacent counties) around the location of its headquarters. We focus on banks founded since 1996 for two reasons. First, this approach helped alleviate the problem of left truncation, a critical issue in research on failure rates. Because all banks entered the sample at or after the beginning of our observation window, no sampled bank had lefttruncated records. Second, focusing on banks founded in or after 1996 was advantageous because pre-1996 biographical information on bank directors was spotty in all three of our data sources. Overall, we were able to carefully obtain biographical information for 1,307 banks (annually updated over an average period of 9.5 years). These banks represented $57 \%$ of the entire population of banks founded during the relevant period. We conducted extensive comparisons between our sample and the remaining banks in this population based on a range of observable characteristics, including bank size, financial profile indicators, location, and mortality, but found no significant differences. Because of 
lagged independent variables, our estimation sample included 9,957 bank-year observations.

\section{Measures}

Dependent variable. Given the regulated nature of the banking industry, the FDIC has direct and ongoing access to information about troubled banks and intervenes when a bank is unable to satisfy its depository obligations. Accordingly, in our empirical definition, a bank failure occurs when the FDIC intervenes in response to a bank's inability to satisfy its depository obligations. Such intervention involves either liquidating the bank or acting as a broker between the focal bank and an acquiring bank that assumes its depository liability. In most cases, the acquiring bank purchases some or all of the failing bank's assets in addition to absorbing its deposits and related obligations, usually at some cost to the FDIC. But if the FDIC is unable to find a buyer at the time of failure, it may retain the bank's assets for later disposition and liquidate the failed bank after paying the required insurance amount directly to depositors. We obtained information about bank failures from SNL Financial.

Alternative outcomes for banks, other than failure, included: (a) survival, (b) merger with another institution that occurred without the above-described type of FDIC intervention (i.e., a type of merger that typically represents a desirable outcome), or (c) bank reorganization (when parent companies recombined their subordinate banks, leaving no trace of the original banks). Of the 1,307 banks in our final sample, 124 (9.5\%) failed, 1,015 survived, and 168 disappeared as a separate entity due to a merger or reorganization that did not involve a failure to meet depository obligations. All these outcomes occurred at the bank (rather than branch) level.

It is worth nothing that the observed failure rate is comparable to rates of failure in the universe of U.S. banks since the early 1990s (based on SNL Financial's bank failure data). While this rate might seem low in comparison to the mortality of new businesses in other industries, it is not surprising given the rigorous regulatory approval process during which prospective bank founders must demonstrate the viability of their proposed venture. Indeed, the failure rate for new banks is consistently lower than the failure rate for new general businesses (e.g., Seballos \& Thomson, 1990).

Independent variables. The variable proportion of banking experts reflected the proportion of directors (at the start of year $t$ ) whose biographical records indicated banking experience before joining the board. Such experience tended to be included in biographical records only if the person in question had previously reached at least the rank of Executive Vice President in a bank. Thus, this variable captured the proportion of directors with substantial experience in the banking domain. Likewise, the variable proportion of real estate experts reflected the proportion of directors whose biographical records indicated a background in the real estate domain (e.g., in real estate development and construction). Typical profiles included owners or top executives of real estate development and real estate investment companies. Both these variables were time-variant and measured annually.

Financial data on a bank's rate of asset growth and the amount of non-standard real estate loans (in millions of dollars) ${ }^{1}$ (both lagged by one year) allowed us to test Hypothesis 1 and Hypothesis 2. To test Hypothesis 3, we measured the number of locally-based banks as the time-variant count of banks based in the focal bank's county. This measure is consistent with our interviewees' accounts that emphasized locally-based banks as the primary direct competitors for our population of interest. To account for variation in the size of the market for banking services across counties, all of our regression models controlled for the dollar value of total deposits in the county. With this control in the models, the number of locally-based banks variable captures how many locally-based banks were competing with the focal bank for a given deposit base.

Control variables. Our analyses controlled for key characteristics of the focal board, the bank, and the environment. At the board level, we controlled for several aspects of board diversity that can affect board effectiveness (Forbes \& Milliken, 1999) and may also be correlated with the proportion of domain experts. We controlled for the diversity of the professional backgrounds of directors using Blau's (1977) index based on 11 common professional categories (banking, real estate, law, medicine, insurance, public sector, military, accounting, other financial, regulatory, and other business). We

\footnotetext{
${ }^{1}$ In loans secured by real estate assets, non-standard real estate loans include land, construction, and development loans, farm loans, large multifamily residential loans, and other non-residential or farming commercial real estate loans. Standard real estate loans involve smaller family residential properties (with one to four units). This categorization reflects the Basel Committee on Banking Supervision report (2006).
} 
captured tenure diversity using the coefficient of variation, that is, the standard deviation of tenure on the board divided by the mean tenure (Williams \& O'Reilly, 1998) and controlled for the proportion of male directors to account for the level of gender diversity. We also included board size (number of directors) at founding, a standard control in the literature on governance and founding teams (Bunderson \& Sutcliffe, 2002; Van Der Vegt \& Bunderson, 2005), which may have important effects on board functioning (see Forbes \& Milliken, 1999). Further, we controlled for turnover (the number of new members who joined the board between the beginning of year $t-1$ and the beginning of year $t$ ) because rapid turnover can signal trouble for a bank and may also be related to changes in the relative proportion of domain experts (see Hambrick \& D’Aveni, 1992).

At the bank level, we controlled for key variables that may be correlated with bank failure: initial asset size (logged to account for skewness), the proportion of brokered bank deposits (lagged), the number of branches, and whether the bank had a parent company. De novo bank, a dummy variable, was coded as 1 if the bank did not have a parent when it filed for regulatory approval.

Finally, to capture environmental factors and economic conditions that might affect the risk of bank failure, we controlled for the annual domestic rate of gross domestic product (GDP) growth (lagged), the total number of bank failures (total bank failures) during the year, and to capture cohort effects, the number of banks founded in the United States in the same year as the focal bank (cohort size). At the county level, to account for aspects of the local competitive landscape that might affect the risk of failure, we controlled for the number of non-local banks, the total value of bank deposits (in millions of dollars), and the level of per capita income in the county (in thousands of dollars).

\section{Statistical Approach}

Competing-risks regression. We tested the hypotheses using competing-risks regression models, treating time to failure as discrete survival time data. Since reorganization and bank merger are other mutually exclusive outcomes for banks, the competingrisks model is more appropriate in this case than a Cox model. A Cox model would inappropriately treat alternative hazards as censored data. However, unlike censoring, which merely prevents one from observing an event, a competing event (e.g., a merger or reorganization) prevents the event of interest (bank failure) from occurring. Thus we used maximum-likelihood estimation to fit competingrisks regression models with multiple-record-persubject survival data (Fine \& Gray, 1999). Like the Cox model, the competing-risks model is semiparametric in that the baseline subhazard for the risk of interest $\hbar_{1,0}(t)$ is left unspecified, while the effects of the covariates $x_{i}$ are assumed to be proportional, an assumption that was confirmed in our data. We specified the following model:

$$
\hbar_{1},\left(\left.t\right|_{X}\right)=\hbar_{1,0},(t) \times \exp \left(\beta_{1} x_{1}+\beta_{2} x_{2}+\ldots+\beta_{k} x_{k}\right) .
$$

As in other survival time models, a shorter time period elapsing between establishment and failure indicates greater likelihood of failing. Thus, this model estimates the relationship between the independent variables and the predicted probability that a bank fails before a certain age, while accounting for other reasons why a bank may disappear from the sample. To obtain robust variance estimates and to account for the existence of multiple observations per bank, we used cluster-adjusted standard errors, which allow for intragroup correlation and represent the default choice of standard errors for competing-risks models with multiple-record data. Using this approach, we report the models that predict the likelihood of bank failures.

To conserve space, we omit models of the competing outcomes (mergers and reorganizations), for which we had no hypotheses. While these models showed no statistically significant relationship between the proportion of banking or real estate experts and the competing outcomes, several of our control variables were significant predictors of mergers and reorganizations. Both these outcomes were more likely in years with higher GDP growth and in counties with higher levels of per capita income. In addition, de novo banks were less likely to undergo reorganization than banks with a parent company.

Inverse-probability-of-treatment-weighted method. One concern about capturing the relationship between a bank's board composition and the probability of failure is that board composition is not randomly assigned and so certain types of banks may be more likely than others to have a higher proportion of domain experts. Thus, if banks that select or attract a higher proportion of domain expert directors are different from banks that tend to have a lower proportion of domain experts, then it is difficult to determine whether observed differences in outcomes (such as bank failure) are attributable to differences in 
the proportion of domain experts or to other bank characteristics. In an ideal experiment, by contrast, the proportion of domain experts would be randomly assigned to banks or, alternatively, each bank would be observed under different (higher and lower) proportions of domain experts on its board. Such an experiment, of course, is impossible. To address this issue, we estimated our models using the inverseprobability-of-treatment-weighted (IPTW) method, a two-stage selection-on-observables estimation technique (Hernán, Brumback, \& Robins, 2000; Robins, Hernán, \& Brumback, 2000) that corrects for each bank's tendency to have an expert-heavy board. IPTW is used commonly in observational research to mitigate selection bias and adjust for non-random treatment (Pontikes, Negro, \& Rao, 2010; Yue, Luo, \& Ingram, 2013). Following the logic of counterfactuals (Winship \& Morgan, 1999), this weighting approach is analogous to simulating what would happen if all banks experienced both high and low proportions of domain experts, thus addressing the possibility that only certain types of banks have a high proportion of domain expert directors.

To implement this method, we first estimated probit models that predicted the probability of each bank having an expert-heavy board (i.e., a board in which the joint proportion of banking and real estate experts was above the median level) using a set of independent variables that emerged from our interviews as potentially relevant. The final model from this analysis appears in Appendix B. This model indicates that banks with a parent company were more likely than de novo banks to have an expert-heavy board. A bank was also more likely to have an expertheavy board if, at the time of founding, there were many existing banks in its county (a proxy for the local supply of potential board members with banking experience) and if GDP growth was high. Boards with a joint chair-CEO also tended to have a higher proportion of domain experts. In addition, there was some variation in the proportion of domain experts depending on the regulator that granted a bank's charter approval: banks that received approval from the Office of the Comptroller of the Currency were especially likely to have an expert-heavy board. Based on these variables, our probit model produced estimated probabilities of receiving the treatment of an expert-heavy board versus the treatment of a nonexpert-heavy board. Then, to test our hypotheses with the IPTW method, we weighted each observation in our main models in inverse proportion to the estimated probability of the treatment that it actually received (Robins et al., 2000).

\section{RESULTS}

Table 1 provides descriptive statistics and bivariate correlations. One noteworthy correlation is the relatively strong negative association between the proportion of bankers and the level of professional diversity $(r=-.48)$. This negative correlation is unsurprising because a very high proportion of bankers implies low professional diversity. At the same time, as our example in the Introduction illustrates, these two variables capture distinct group characteristics. Indeed, this correlation coefficient implies that the diversity variable explains only $23 \%$ of the variation in the proportion of experts (i.e., $r^{2}=$ $0.48^{2}=.23$ ); the remaining $77 \%$ of variation in the proportion of experts is not captured by diversity. Moreover, our results remain similar whether professional diversity is included or not, suggesting that collinearity between the two variables did not influence the results. Finally, supplementary analyses show that replacing the proportion of experts with professional diversity in our hypothesized interaction terms does not produce similar results as our primary analyses, a result consistent with the idea that these two variables have distinct effects. ${ }^{2}$

Table 2 presents tests of the hypotheses. Model 1 includes only the main independent variables and the controls, without the hypothesized interactions. Models 2, 3, and 4 examine bank failure as a function of the interaction between the proportion of domain experts and asset growth (Hypothesis 1), non-standard real estate lending (Hypothesis 2), and the number of locally-based banks (Hypothesis 3), respectively. Model 5 includes all the interaction terms together in one model. In these models, a positive coefficient indicates that a particular variable increases the predicted likelihood of failure; a negative coefficient implies a decreased probability of failure. Coefficients in competing risks models, however, do not provide a simple, intuitive interpretation

\footnotetext{
${ }^{2}$ Table 1 also shows that the proportion of domain experts was not significantly correlated with asset growth or involvement in non-standard real estate lending, and only had weak association with the number of locally-based banks in the area. This is consistent with our informants' accounts suggesting that these conditions are influenced by several factors exogenous to the composition of boards, such as the tolerance of regulators for different growth and lending aspirations at the time of approving a bank's business plan. Regulators' approach to business plans, in turn, is likely to be shaped by macroeconomic forecasts at the time as well as idiosyncratic factors, such as the regulator's recent experiences with failed banks.
} 


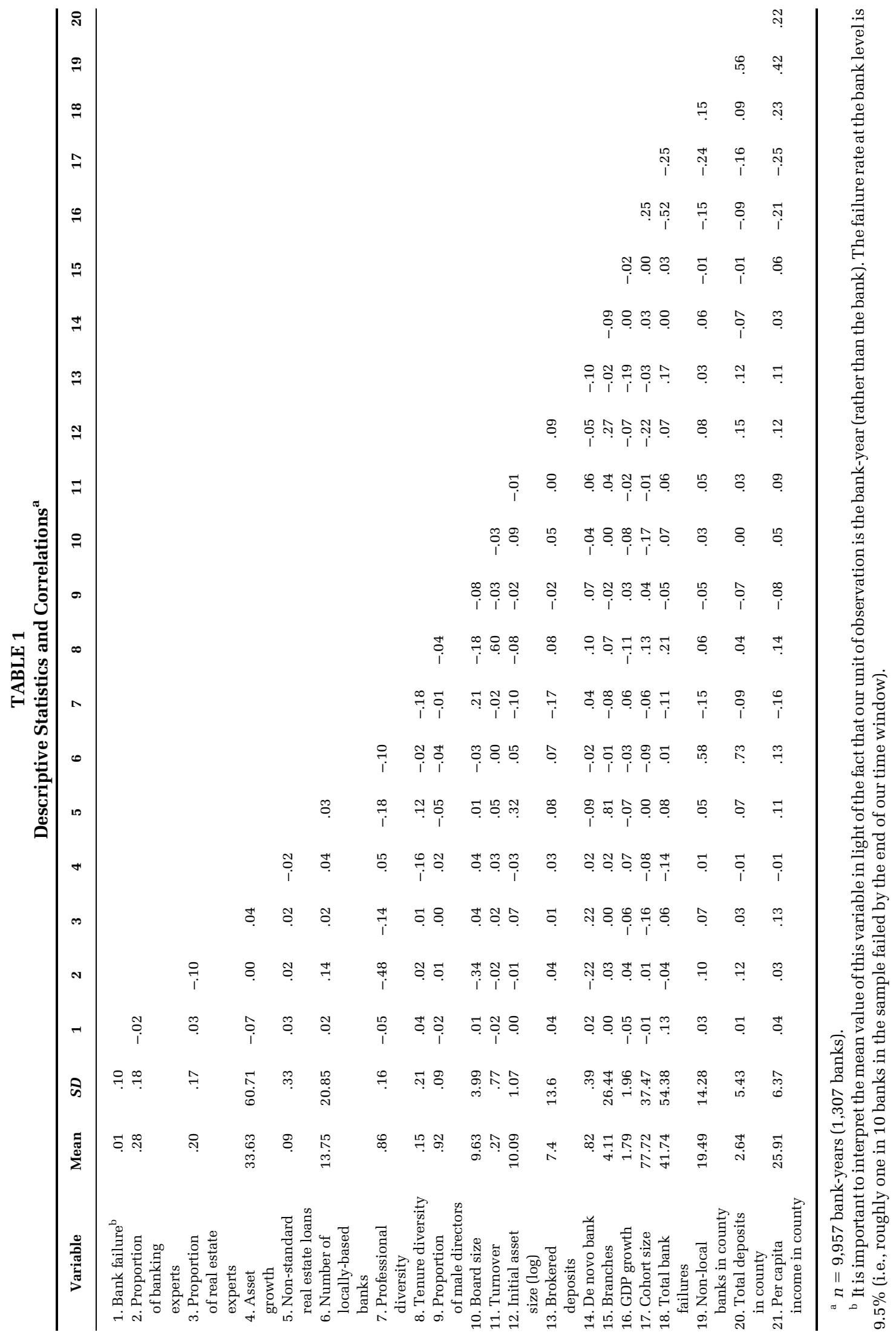


TABLE 2

Coefficients for Competing-Risks Models Predicting Bank Failure ${ }^{a}$

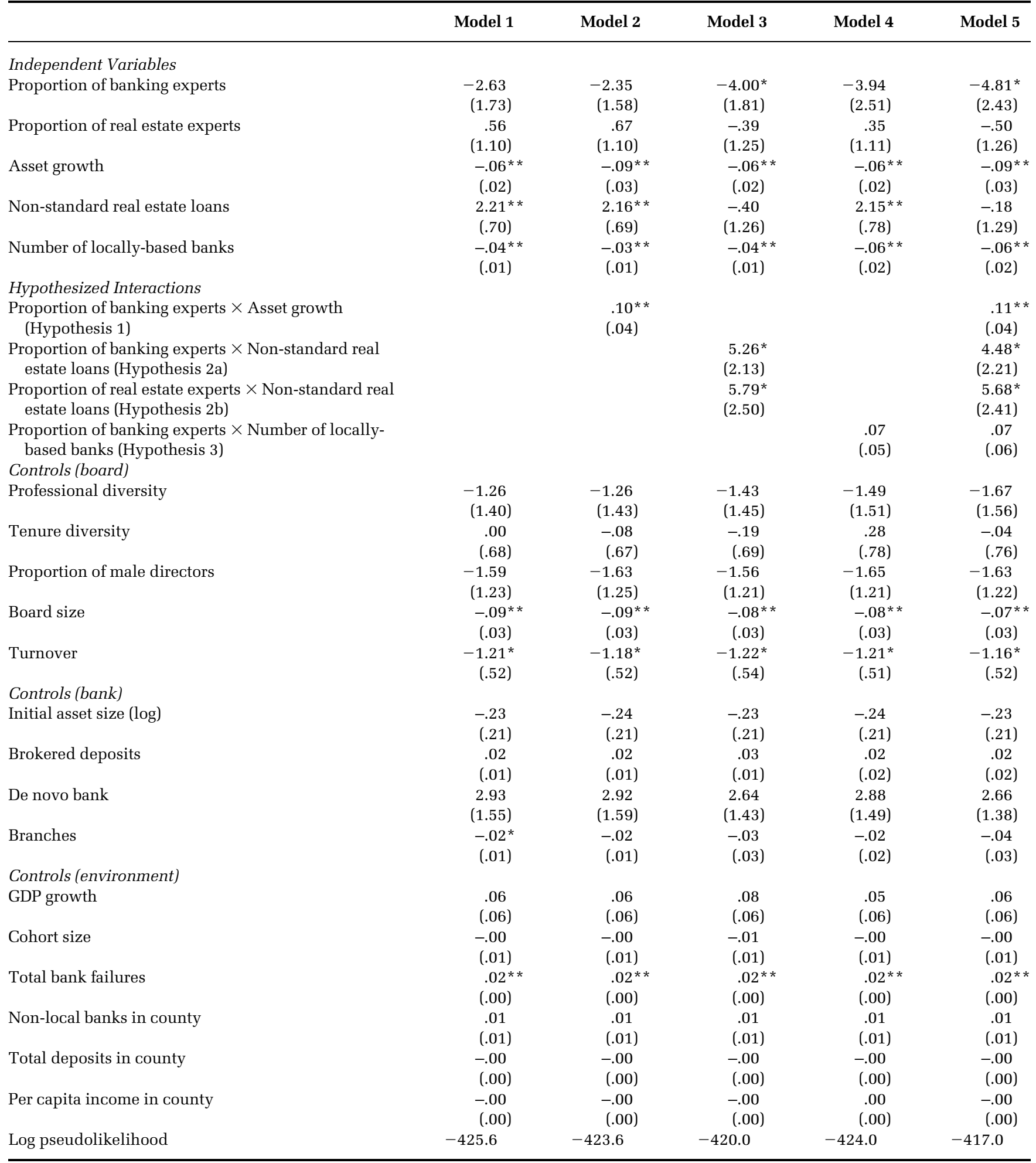

${ }^{\text {a }} n=9,957$ bank-years (1,307 banks). Robust standard errors, adjusted for clustering by bank $\mathrm{ID}$, are in parentheses. All models include state dummies.

${ }^{*} p<.05$

$* * p<.01$ 
of effect size. Thus, after presenting our regression analysis, we use figures to illustrate effect sizes.

A key result of theoretical interest from Model 1 is that the proportion of directors who were banking or real estate experts had no significant main effect on bank failure. That is, there is no evidence that having a higher proportion of domain expert directors would automatically lead to higher or lower probability of failure. Rather, as we theorized, and as the subsequent models indicate, the relationship between the proportion of domain experts and the risk of bank mortality was contingent on the level of decision uncertainty.

First, as predicted, Models 2 and 5 show that a bank's asset growth moderates the relationship between the proportion of banking experts and the likelihood of bank failure: When the focal bank's asset growth rate was high rather than low, the proportion of banking expert directors was more strongly related to the risk of failure. This finding provides support for Hypothesis 1. Second, Models 3 and 5 are consistent with both Hypothesis $2 \mathrm{a}$ and Hypothesis 2b. The greater a bank's involvement in non-standard real estate lending, the stronger the relationship between the proportion of directors who are domain experts (in banking and real estate) and the probability of bank failure. Third, although the coefficient estimate for the interaction term relevant to Hypothesis 3 is in the predicted direction in Models 4 and 5, it is not significant. Overall, the results support Hypothesis 1, Hypothesis 2a, and Hypothesis $2 \mathrm{~b}$.

To help interpret our results, Figures 1, 2, and 3 reflect the estimates of our competing-risks models to illustrate how the predicted cumulative incidence of failure varies by the proportion of domain experts on the board and by the level of decision uncertainty. Thus, these figures show the predicted probability, under different conditions, that a bank will fail before reaching a certain age.

Figures 1 and 2 display results relevant to $\mathrm{Hy}$ pothesis 1 and Hypothesis 2a under different conditions of decision uncertainty. Both these figures compare predicted failure rates for banks in which $50 \%$ of the directors are banking experts versus those in which only $10 \%$ are banking experts, corresponding to roughly one standard deviation above and below the mean proportion of banking experts. Figure 3, which focuses on Hypothesis $2 \mathrm{~b}$, displays predicted failure rates for banks in which $40 \%$ of the directors are real estate experts versus those in which $10 \%$ are real estate experts, which corresponds to roughly one standard deviation above and below the mean proportion of real estate experts, except that we set the low proportion of real estate experts at $10 \%$, rather than $3 \%$, because the former is more meaningful as the average board consisted of roughly 10 directors. All three figures display the cumulative incidence of failure over a 15-year period, a time span that corresponds to the approximate range for age in our data. In each figure, the relevant moderating variable is set at its 15th percentile (low level) and 85th percentile (high level) to ensure that plotted values are within the range of actual observations.

Figure 1 pertains to Hypothesis 1. Given the negative association between asset growth and failure (as banks on the verge of failure do not tend to grow fast), the two red lines, which show the likelihood of failure under fast asset growth, are below the black lines, which indicate slow asset growth. What is most relevant to Hypothesis 1 is that, while the two black lines remain fairly close to each other over time, the gap between the two red lines is relatively large. This suggests that under slow asset growth (i.e., limited decision uncertainty), the proportion of banking experts on the board has relatively little effect on failure rates, but under fast asset growth, the proportion of banking expert directors is clearly associated with a higher risk of failure (although the level of this risk is still lower than it is under conditions of slow growth).

Figure 2 illustrates Hypothesis 2a. This figure shows that when the focal bank is engaged in a substantial amount of non-standard real estate lending (shown by the red lines), the probability of failure is clearly higher with a higher proportion of banking experts on the board than with a lower proportion of banking experts. In contrast, when a bank is mostly engaged in standard real estate lending, having a high rather than low proportion of banking expert directors is actually associated with a somewhat lower failure rate.

Finally, Figure 3 displays patterns relevant to Hypothesis $2 \mathrm{~b}$. When a bank is engaged in a substantial amount of non-standard real estate lending, then a higher proportion of real estate experts on the board is clearly associated with a higher likelihood of failure. However, when a bank is mostly engaged in standard real estate lending, the proportion of real estate experts on the board has limited effect on bank mortality.

\section{Additional Analyses}

To investigate the possibility of a curvilinear relationship between the proportion of domain experts and bank mortality, we conducted supplementary analyses by entering the squared term for the proportion of banking (or real estate) experts into our regression 
FIGURE 1

Predicted Cumulative Incidence of Failure for Banks under Slow and Fast Asset Growth, by Proportion of Banking Experts on the Board

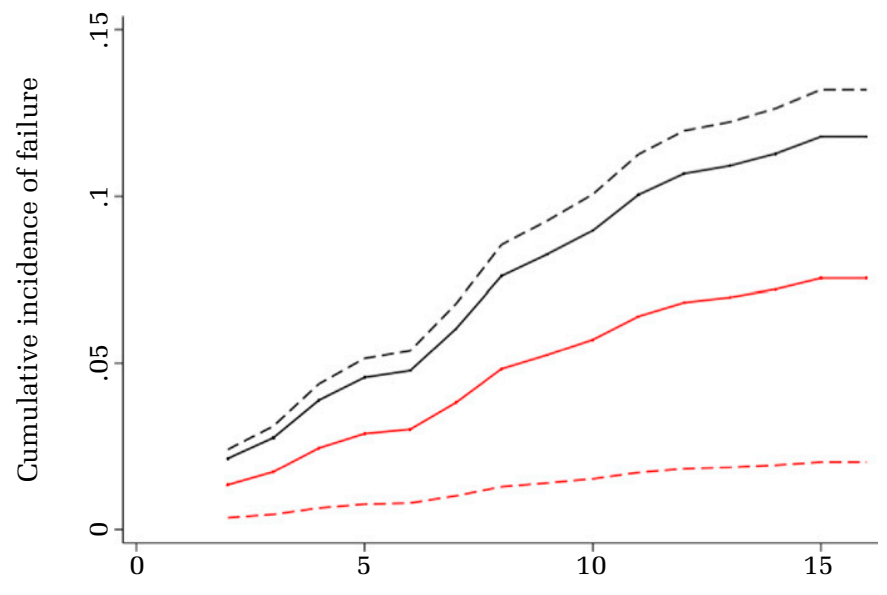

Time (years)

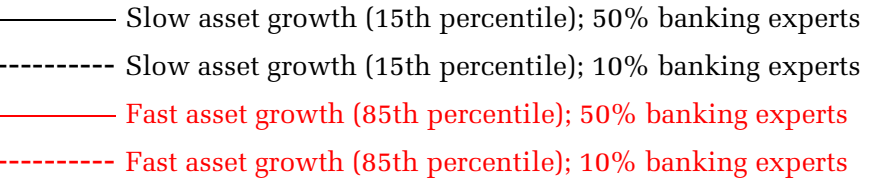

equation. As an additional approach to possible curvilinearity, we divided the proportion of banking (or real estate) experts into quartile dummies. We found no evidence for a curvilinear relationship between the proportion of domain experts and the risk of bank failure with either approach.

Another question unaddressed in our main analysis is whether the effect of the proportion of domain experts is visible even when examining more proximate indicators of financial trouble than bank failure. Of course, one attractive aspect of actual failure as a dependent variable is that it is not based on self-reported accounting data and is therefore insusceptible to manipulation and less noisy than other measures. While an actual bank failure is a clear and undeniable sign of financial trouble, a struggling bank may be able to present parts of its accounting data in a way that downplays some of its problems. Indeed, despite standard accounting rules on paper, there is some latitude in practice regarding what to classify as a nonperforming loan or asset. In addition, failures to enforce internal controls, and even legal violations, may lead some banks to underreport financial problems. Thus, the accuracy of accounting-based indicators may be tainted by differences in banks' transparency in reporting lending mistakes (e.g., United States General Accounting Office, 1991). For these reasons, the relationships between our variables of interest and accounting-based outcome measures may be noisy.

Nevertheless, we examined whether the interaction terms of theoretical interest predict two key indicators of financial trouble (Getter, 2014): (1) non-current loans (i.e., loans that are overdue or in non-accrual status) as a percentage of assets, and (2) non-performing assets (which includes loans, debt securities, and other assets that are not accruing interest, as well as restructured loans and foreclosed or repossessed properties) as a percentage of equity capital. As Models C1 and C2 in Appendix $\mathrm{C}$ show, several results from these analyses parallel our main findings, but as we expected, effects on accounting-based measures are more noisily estimated and not as clearly visible in the data as effects on the unambiguous outcome of actual failure.

A related question is whether these indicators of financial trouble mediate the relationship between the hypothesized interaction terms and bank failure. Following Baron and Kenny's (1986) procedure, the first step in this mediation analysis is to show that our interaction terms of interest are correlated with bank failure. The models in Table 2 establish these 
FIGURE 2

Predicted Cumulative Incidence of Failure for Banks under Low and High Levels of Non-Standard Real Estate Loans, by Proportion of Banking Experts on the Board
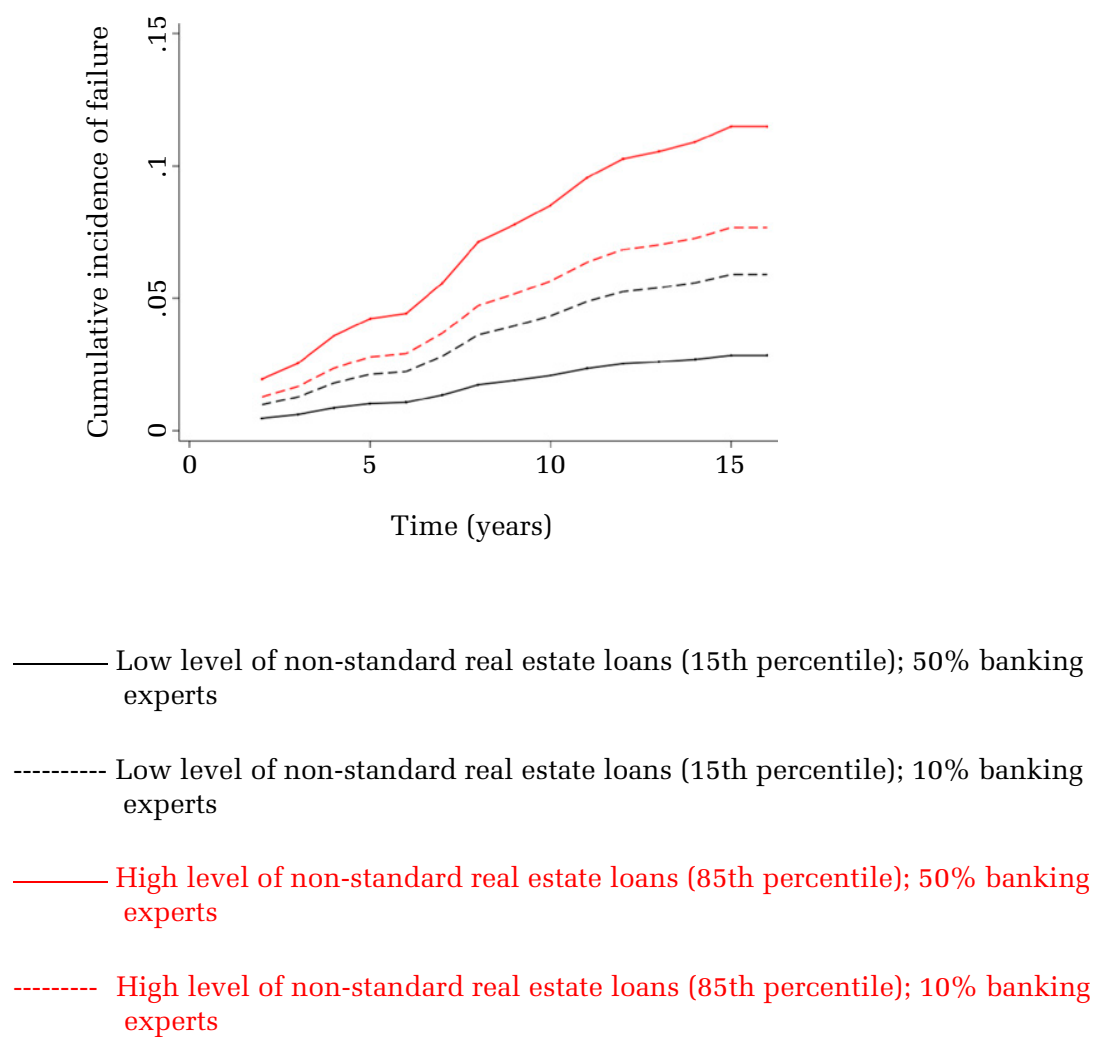

correlations. The second step is to show that the interaction terms are correlated with the potential mediator, that is, our indicators of financial trouble. Models C1 and C2 in Appendix C provide some evidence for these correlations. The third and fourth steps involve estimating a regression equation that predicts the ultimate outcome (bank failure) as a function of the hypothesized interactions as well as the financial trouble indicators. Models C3 and C4 in Appendix $\mathrm{C}$ show these equations. These models are identical to Model 5 in Table 2 except that, unlike Model 5, they control for non-current loans and nonperforming assets. Consistent with a mediation pattern, the coefficient on non-current loans and non-performing assets is statistically significant in these equations, while most coefficients for our hypothesized interactions are no longer significant. This suggests that financial performance (as measured by our accounting indicators) almost completely mediates the relationship between the proportion of domain experts and the risk of bank failure.

Finally, we also considered the alternative account that, while the proportion of domain expert directors is related to bank failure under some conditions, it might also be associated with higher returns. Therefore, using a series of supplementary models, we estimated the effect of the proportion of domain experts on a bank's return on average equity and return on average assets but found no systematic relationship, either in the absence or the presence of conditions associated with increased decision uncertainty.

\section{DISCUSSION}

Given the importance of effective corporate boards in governance and strategic decision making, it is imperative to understand which dimensions of boards are most consequential and how exactly those dimensions matter for organizational outcomes (Dalton \& Dalton, 2011; Forbes \& Milliken, 1999; McNulty, 2013). To date, although a voluminous literature has focused on the composition of boards, it has revealed relatively few consistent links between board composition and corporate financial health (Dalton et al., 1998; Dalton \& Dalton, 2011). Our study introduces the relative representation of domain 
FIGURE 3

Predicted Cumulative Incidence of Failure for Banks under Low and High Levels of Non-Standard Real Estate Loans, by Proportion of Real Estate Experts on the Board

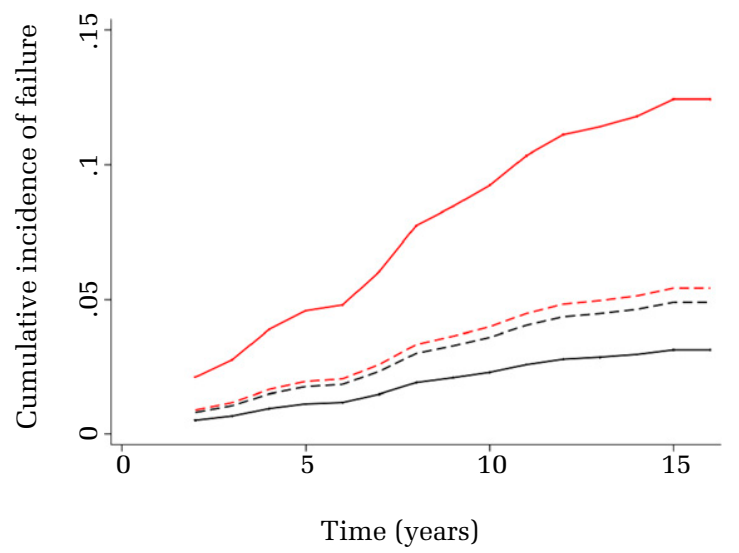

\footnotetext{
L Low level of non-standard real estate loans (15th percentile); 40\% real estate experts

--------- Low level of non-standard real estate loans (15th percentile); 10\% real estate experts

High level of non-standard real estate loans (85th percentile); $40 \%$ real estate experts

High level of non-standard real estate loans (85th percentile); $10 \%$ real estate experts
}

expert directors versus non-expert board members as a key aspect of board composition. In theorizing the relationship between this variable and a firm's survival chances, we have developed the argument that the relationship between the proportion of domain experts on a board and the risk of organizational failure is contingent on the level of decision uncertainty. Consistent with this proposition, our results show that the positive relationship between the proportion of domain experts on local banks' boards and the probability of bank failure is stronger when decision uncertainty is high rather than low. These findings have theoretical implications for the specific dimensions of board composition that matter for firms' financial health, the conditions under which the professional background of directors is more or less consequential, and the mechanisms by which the makeup of a board affects organizational outcomes.

At the most basic level, this research extends our understanding of what the critical features of board composition are. Shifting the scholarly conversation away from the traditional focus on board diversity, we highlight the proportion of domain experts as a distinct and highly consequential characteristic of corporate boards. Accordingly, our results show that the proportion of domain expert directors was related to a vital organizational outcome-survival or failureeven after accounting for the influence of professional, tenure, and gender diversity on boards. Although often overlooked in prior research (Dalton et al., 1998; Dalton \& Dalton, 2011; Forbes \& Milliken, 1999), we suggest that the presence of domain experts is a potentially critical factor in understanding the consequences of board composition on organizations.

Highlighting this factor as a key dimension of board composition is especially important in advancing our understanding of boards because the effect of domain expert directors on organizational outcomes is far from obvious. Indeed, in our context, the idea that expert-dominated boards might have serious negative consequences for organizations clearly defies conventional wisdom. Our interviews suggest that regulators, consultants, and many bank 
founders favor domain experts as directors because they see them as essential for navigating local banks under uncertain conditions. Thus, as our informants consistently noted, "if you have people with banking experience at the board level, [regulators and investors] love to see that." Contrary to this optimistic view of expert-dominated boards, however, we show that a high proportion of banking expert directors may actually hurt banks' survival chances. More generally, despite the perception that the value of domain experts comes from their ability to manage uncertainty (see Shapira, 1995), we show that, ironically, it is precisely under conditions of uncertainty that a higher proportion of domain experts is associated with organizational mortality. This finding advances our understanding of corporate boards by highlighting an important counter-intuitive effect of board composition on organizational survival.

A crucial feature of our contingency perspective is that it does not simply posit an automatic relationship between the proportion of domain experts and organizational failure. Rather, it specifies the boundaries of our core hypothesis and emphasizes the theoretical importance of decision uncertainty (Elbanna \& Child, 2007) for influencing the extent to which board composition matters for organizational outcomes. Thus, this perspective contributes to the literature on board composition by clarifying the conditions under which the professional makeup of boards matters the most. Although a large literature has explored the effects of board composition on organizations, our understanding of when board composition is more or less consequential has been limited. Our research helps advance this literature by moving beyond a focus on simple, unmoderated main effects to illuminate decision uncertainty as an important contingency in the relationship between board composition and organizational outcomes.

In developing this contingency argument, this study has also theorized and qualitatively explored the mechanisms that underlie our central hypothesis. Thus, we shed new light on some of the mechanisms by which board composition can affect strategic decision making and, ultimately, the fate of an organization. Building on prior research and our interviews, we point to the influence of cognitive entrenchment and overconfidence as potential mechanisms that are specifically associated with higher proportions of domain experts, rather than simply a limited degree of professional diversity. In addition, as we noted, while one might expect less task conflict whenever a large proportion of group members are from a single profession, limited task conflict may be especially likely if that profession is identified with expertise in the focal domain. These possible mechanisms, in turn, imply that a higher proportion of non-experts might benefit corporate boards under some conditions by potentially limiting the influence of domain experts' entrenchment and overconfidence on group decisions and perhaps by contributing to more critical or cautious group deliberations during which members can voice concerns and dissenting opinions. At the same time, observations from our exploratory interviews are suggestive rather than conclusive. Thus, this study opens a path for more systematic future research into decision-making processes in boards with different proportions of domain experts.

Finally, our research also holds practical implications for creating effective boards, especially in the banking sector. Our findings suggest that the proportion of domain expert directors is an important variable to consider in board design. Indeed, this variable might be particularly important from a practical point of view because it is an easily visible dimension of board composition that an organization can readily influence when forming a board or adding new directors (see Almandoz, 2012; Pfeffer, 1972). Our findings caution against the assumption that a higher proportion of domain experts will necessarily make boards more effective. At the same time, when interpreting our results, it is important to bear in mind that most boards in our empirical context include at least two directors with prior banking experience to fulfill minimum regulatory requirements of financial expertise (see Almandoz, 2012). Thus, our findings should not be taken to imply that boards with no domain experts whatsoever are optimal; rather, what our results point to is the importance of appointing a non-trivial number of directors with primary expertise beyond the focal domain, especially in boards that are likely to face a significant degree of decision uncertainty.

\section{Limitations, Boundary Conditions, and Future Research}

This study is not without limitations, some of which suggest important avenues for future research. First, we empirically focused only on banks that were established after 1996. As we noted, this focus offered significant empirical advantages because it allowed us to avoid missing data problems and, most important, the problem of left truncation. The focus on relatively young banks, however, does raise the question of whether the effects we observe fade with 
organizational age. Thus, we conducted a series of supplementary analyses to explore whether bank age moderates the proposed relationships but found no evidence for the fading of these effects with age. It is of course possible that banks in our sample were not tracked long enough (an average of 9.5 years, with a maximum age of 16 years) for the influence of age to be observable. Organizational age may thus be a potential boundary condition worth exploring in future research.

Second, one concern is that our time window (1996-2012) may be somewhat abnormal because it includes the financial crisis of 2007-2008 during which an unusually large number of banks failed in the United States. Clearly, in a highly stable and "forgiving" economic context, when even poorly managed banks are unlikely to fail, board composition may have less dramatic consequences than in the midst of a financial crisis. At the same time, most years within our time window did not involve a financial crisis, and overall failure rates in our time period were not substantially higher or lower than failure rates in most decades between 1920 and 1990 (see Alston, Grove, \& Wheelock, 1994; Seballos \& Thomson, 1990). Moreover, our models accounted for year-to-year variation in economic conditions by controlling for the rate of GDP growth and the number of bank failures each year. In addition, as a robustness check, we performed supplementary analyses in which we dropped observations from 2008 and 2009, the years that included quarters during which the U.S. economy was in recession following the peak of December 2007 (National Bureau of Economic Research, 2014), and our results, even if somewhat less statistically precise, were similar to those in our main models. Future research might further examine our research question specifically under extremely volatile economic conditions or, conversely, in particularly stable and prosperous environments.

Third, one limitation of our dataset is that it does not allow us to explore the possibility that some domain experts are less prone to tendencies like cognitive entrenchment or overconfidence. Dane (2010) argues that some experts in a given domain may exhibit less entrenchment if they also focus attention on tasks in other domains or if they have repeatedly experienced changing conditions and unexpected outcomes within their own domain, which might lead them to question otherwise taken-for-granted assumptions in the domain. Because we lack sufficiently detailed information about the careers of bankers to distinguish degrees of prior exposure to outside domains and to volatile or unexpected conditions in the banking domain, we encourage future research on how such heterogeneity may moderate the relationships that we documented.

Fourth, another potential boundary condition concerns the way we have conceptualized and measured decision uncertainty. In each case-rapid asset growth, non-standard real estate lending, and a high number of local competitors-the decisions in responding to these types of uncertainty tend to be familiar decisions that boards and, in particular, domain experts are likely to have faced previously. It remains an open question whether the relationships that we have documented will also hold under different, largely unfamiliar kinds of uncertainty, such as the introduction of dramatically new regulations or the emergence of new types of competition.

Finally, the extent to which our hypotheses apply to contexts beyond banking is a crucial question that warrants additional empirical research. For example, in industry settings in which boards of directors tend to be less directly and actively involved in strategic decision making than in the case of local banks, the relationship between the proportion of domain expert directors and the likelihood of organizational survival might be less pronounced. It is also possible that, in some industry settings, the legitimacy that boards comprised of higher proportions of domain experts might confer on a firm (see Daily \& Schwenk, 1996; Lynall et al., 2003) is so important to corporate performance and survival that it counterbalances the effects documented in our study. Moreover, psychological research suggests that in some contexts domain experts may exhibit less overconfidence or make less extreme judgments than do non-experts (e.g., Brauer, Chambres, Niedenthal, \& ChatardPannetier, 2004). While the definition of experts in this line of research is different from our more sociological definition, the core issue of the transferability of our findings to domains beyond banking remains to be addressed empirically.

\section{CONCLUSION}

The impact of board composition on organizations is a topic of considerable interest to organizational scholars as well as managers and regulators attempting to improve corporate governance and decision making. Consequently, a rich literature has explored how board composition can influence organizational outcomes. Our study contributes to this literature by showing that the proportion of domain experts is a critical yet previously overlooked dimension of board composition, which may have 
dramatic consequences for the fate of organizations. Although domain experts on boards are often touted as invaluable to effective decision making, we find that-under conditions of decision uncertaintyhigher proportions of domain expert directors may actually lead to greater likelihood of organizational failure. Our study unpacks this relationship and offers insights into the contingent effects of board composition on organizations.

\section{REFERENCES}

Achrol, R. S., \& Stern, L. W. 1988. Environmental determinants of decision-making uncertainty in marketing channels. JMR, Journal of Marketing Research, 25: 36-50.

Almandoz, J. 2012. Arriving at the starting line: The impact of community and financial logics on new banking ventures. Academy of Management Journal, 55: 1381-1406.

Almandoz, J. 2014. Founding teams as carriers of competing logics: When institutional forces predict banks' risk exposure. Administrative Science Quarterly, 59: 444-473.

Alpert, M., \& Raiffa, H. 1982. A progress report on the training of probability assessors. In D. Kahneman, P. Slovic, \& A. Tversky (Eds.), Judgment under uncertainty: Heuristics and biases: 294-305. New York, NY: Cambridge University Press.

Alston, L. J., Grove, W. A., \& Wheelock, D. C. 1994. Why do banks fail? Evidence from the 1920s. Explorations in Economic History, 31: 409-431.

Amason, A. C. 1996. Distinguishing the effects of functional and dysfunctional conflict on strategic decision making: Resolving a paradox for top management teams. Academy of Management Journal, 39: 123-148.

Angner, E. 2006. Economists as experts: Overconfidence in theory and practice. Journal of Economic Methodology, 13: 1-24.

Baker, H. K., \& Powell, G. 2009. Management views on corporate governance and firm performance. In M. Hirschey, K. John, \& A. K. Makhija (Eds.), Advances in financial economics: Corporate governance and firm performance: $83-118$. Bingley, UK: Emerald Group Publishing Limited.

Baron, R. M., \& Kenny, D. A. 1986. The moderatormediator variable distinction in social psychological research: Conceptual, strategic, and statistical considerations. Journal of Personality and Social Psychology, 51: 1173-1182.

Basel Committee on Banking Supervision 2006. Basel II: International convergence of capital measurement and capital standards: A revised framework-Comprehensive version. Available from http://www.bis.org/publ/ bcbs128.pdf, accessed July 2, 2014.
Baysinger, B. D., \& Butler, H. N. 1985. Corporate governance and the board of directors: Performance effects of changes in board composition. Journal of Law Economics and Organization, 1: 101-124.

Beach, L. R., \& Mitchell, T. R. 1978. A contingency model for the selection of decision strategies. Academy of Management Review, 3: 439-449.

Ben-David, I., Graham, J., \& Harvey, C. 2013. Managerial miscalibration. The Quarterly Journal of Economics, 128: 1547-1584.

Blau, P. M. 1977. Inequality and heterogeneity: A primitive theory of social structure, vol. 7, New York, NY: Free Press.

Brauer, M., Chambres, R., Niedenthal, P., \& ChatardPannetier, A. 2004. The relationship between expertise and evaluative extremity: The moderating role of experts' task characteristics. Journal of Personality and Social Psychology, 86: 5-18.

Brenner, L. A., Koehler, D. J., Liberman, V., \& Tversky, A. 1996. Overconfidence in probability and frequency judgments: A critical examination. Organizational Behavior and Human Decision Processes, 65: 212-219.

Bunderson, J. S., \& Sutcliffe, K. M. 2002. Comparing alternative conceptualizations of functional diversity in management teams: Process and performance effects. Academy of Management Journal, 45: 875-893.

Busenitz, L. W., \& Barney, J. B. 1997. Differences between entrepreneurs and managers in large organizations: Biases and heuristics in strategic decision-making. Journal of Business Venturing, 12: 9-30.

Chaganti, R. S., Mahajan, V., \& Sharma, S. 1985. Corporate board size, composition and corporate failures in retailing industry. Journal of Management Studies, 22: 400-417.

Christensen-Szalanski, J. J., \& Bushyhead, J. B. 1981. Physicians' use of probabilistic information in a real clinical setting. Journal of Experimental Psychology. Human Perception and Performance, 7: 928-935.

Cooke, R. M. 1991. Experts in uncertainty: Opinion and subjective probability in science. Oxford, UK: Oxford University Press.

Daily, C. M., \& Dalton, D. R. 1994. Corporate governance and the bankrupt firm: An empirical assessment. Strategic Management Journal, 15: 643-654.

Daily, C. M., \& Schwenk, C. 1996. Chief executive officers, top management teams, and boards of directors: Congruent or countervailing forces? Journal of Management, 22: 185-208.

Dalton, D. R., Daily, C. M., Ellstrand, A. E., \& Johnson, J. L. 1998. Meta-analytic reviews of board composition, leadership structure, and financial performance. Strategic Management Journal, 19: 269-290. 
Dalton, D. R., \& Dalton, C. M. 2011. Integration of micro and macro studies in governance research: CEO duality, board composition, and financial performance. Journal of Management, 37: 404-411.

Dane, E. 2010. Reconsidering the trade-off between expertise and flexibility: A cognitive entrenchment perspective. Academy of Management Review, 35: 579-603.

Davis, J. P., Eisenhardt, K. M., \& Bingham, C. B. 2009. Optimal structure, market dynamism, and the strategy of simple rules. Administrative Science Quarterly, 54: 413-452.

Dean, J. W., \& Sharfman, M. P. 1993. The relationship between procedural rationality and political behavior in strategic decision making. Decision Sciences, 24: 1069-1083.

Dencker, J. C., Gruber, M., \& Shah, S. K. 2009. Pre-entry knowledge, learning, and the survival of new firms. Organization Science, 20: 516-537.

Derber, C., Schwartz, W. A., \& Magrass, Y. 1990. Power in the highest degree: Professionals and the rise of a new Mandarin order. Oxford, UK: Oxford University Press.

DiMaggio, P. J., \& Powell, W. W. 1983. The iron cage revisited: Institutional isomorphism and collective rationality in organizational fields. American Sociological Review, 48: 147-160.

Elbanna, S., \& Child, J. 2007. Influences on strategic decision effectiveness: Development and test of an integrative model. Strategic Management Journal, 28: 431-453.

Evetts, J., Mieg, H. A., \& Felt, U. 2006. Professionalization, scientific expertise, and elitism: A sociological perspective. In K. A. Ericsson, N. Charness, P. Feltovich, \& R. R. Hoffman (Eds.), The Cambridge handbook of expertise and expert performance: 105-123. Cambridge, UK: Cambridge University Press.

Fellner, G., \& Krügel, S. 2010. Overweighting private information: Three measures, one bias? Working paper No. 2010-58, Jena Economic Research Papers.

Fine, J. P., \& Gray, R. J. 1999. A proportional hazards model for the sub distribution of a competing risk. Journal of the American Statistical Association, 94: 496-509.

Fischhoff, B., Slovic, P., \& Lichtenstein, S. 1977. Knowing with certainty: The appropriateness of extreme confidence. Journal of Experimental Psychology. Human Perception and Performance, 3: 552-564.

Fogel, E. M., \& Geier, A. M. 2007. Strangers in the house: Rethinking Sarbanes-Oxley and the independent board of directors. The Delaware Journal of Corporate Law, 32: 33-72.

Foos, D., Norden, L., \& Weber, M. 2010. Loan growth and riskiness of banks. Journal of Banking \& Finance, 34: 2929-2940.
Forbes, D. P., \& Milliken, F. J. 1999. Cognition and corporate governance: Understanding boards of directors as strategic decision-making groups. Academy of Management Review, 24: 489-505.

Freidson, E. 1986. Professional powers. Chicago: University of Chicago Press.

Freidson, E. 2001. Professionalism: The third logic. Chicago: University of Chicago Press.

Friedkin, N. E. 1999. Choice shift and group polarization. American Sociological Review, 64: 856-875.

Furr, N. R., Cavarretta, F., \& Garg, S. 2012. Who changes course? The role of domain knowledge and novel framing in making technology changes. Strategic Entrepreneurship Journal, 6: 236-256.

Gerver, I., \& Bensman, J. 1954. Towards a sociology of expertness. Social Forces, 32: 226-235.

Getter, D. E. 2014. Financial condition of depository banks. Congressional Research Service. Available from http://www.fas.org/sgp/crs/misc/R43002.pdf, accessed July 19, 2014.

Glaser, M., Langer, T., \& Weber, M. 2013. True overconfidence in interval estimates: Evidence based on a new measure of miscalibration. Journal of Behavioral Decision Making, 26: 405-417.

Hambrick, D. C., \& D’Aveni, R. A. 1992. Top team deterioration as part of the downward spiral of large corporate bankruptcies. Management Science, 38: 1445-1466.

Harrison, D. A., \& Klein, K. J. 2007. What's the difference? Diversity constructs as separation, variety, or disparity in organizations. Academy of Management Review, 32: 1199-1228.

Haveman, H. A. 1992. Between a rock and a hard place: Organizational change and performance under conditions of fundamental environmental transformation. Administrative Science Quarterly, 37: 48-75.

Henrion, M., \& Fischhoff, B. 1986. Uncertainty assessment in the estimation of physical constants. American Journal of Physics, 54: 791-798.

Hernán, M. Á., Brumback, B., \& Robins, J. M. 2000. Marginal structural models to estimate the causal effect of zidovudine on the survival of HIV-positive men. Epidemiology (Cambridge, Mass.), 11: 561-570.

Isenberg, D. J. 1986. Group polarization: A critical review and meta-analysis. Journal of Personality and Social Psychology, 50: 1141-1151.

Jehn, K. A. 1995. A multimethod examination of the benefits and detriments of intragroup conflict. Administrative Science Quarterly, 40: 256-282.

Kaplan, S. 2008. Framing contests: Strategy making under uncertainty. Organization Science, 19: 729-752. 
Kobelsky, K., Hunter, S., \& Richardson, V. J. 2008. Information technology, contextual factors and the volatility of firm performance. International Journal of Accounting Information Systems, 9: 154-174.

Kor, Y. Y., Mahoney, J. T., \& Watson, S. 2008. The effects of demand, competitive, and technological uncertainty on board monitoring and institutional ownership of IPO firms. Journal of Management and Governance, 12: 239-259.

Leblebici, H., \& Salancik, G. 1981. Environmental effects of uncertainty on information and decision processes in banks. Administrative Science Quarterly, 26: 578-596.

Lin, S. W., \& Bier, V. M. 2008. A study of expert overconfidence. Reliability Engineering \& System Safety, 93: 711-721.

Lynall, M. D., Golden, B. R., \& Hillman, A. J. 2003. Board composition from adolescence to maturity: A multitheoretic view. Academy of Management Review, 28: 416-431.

McNulty, T. 2013. Process matters: Understanding board behavior and effectiveness. In M. Wright, D. S Siegel, \& I. Filatotchev (Eds.), The Oxford handbook of corporate governance: 163-176. Oxford, UK: Oxford University Press.

Mellahi, K., \& Wilkinson, A. 2004. Organizational failure: A critique of recent research and a proposed integrative framework. International Journal of Management Reviews, 5: 21-41.

Meyer, J. W., \& Rowan, B. 1977. Institutionalized organizations: Formal structure as myth and ceremony. American Journal of Sociology, 83: 340-363.

Mieg, H. A. 2006. System experts and decision making experts in transdisciplinary projects. International Journal of Sustainability in Higher Education, 7: 341-351.

Miles, M. B., \& Huberman, A. M. 1994. Qualitative data analysis: An expanded sourcebook. London: Sage Publications.

Milliken, F. J., \& Martins, L. L. 1996. Searching for common threads: Understanding the multiple effects of diversity in organizational groups. Academy of Management Review, 21: 402-433.

Moore, D. A., \& Healy, P. J. 2008. The trouble with overconfidence. Psychological Review, 115: 502-517.

Murphy, A. H., \& Winkler, R. L. 1977. Reliability of subjective probability forecasts of precipitation and temperature. Applied Statistics, 26: 41-47.

Murphy, A. H., \& Winkler, R. L. 1982. Subjective probability of tornado forecasts: Some experimental results. Monthly Weather Review, 110: 1288-1297.

National Bureau of Economic Research 2014. US business cycle expansions and contractions. Available from http://www.nber.org/cycles/cyclesmain.html, accessed July 1, 2014.
Office of the Comptroller of the Currency 2001. Problem bank identifications, rehabilitation, and resolution. Available from http://www.occ.gov/publications/ publications-by-type/other-publications-reports/ prbbnkgd.pdf, accessed July 19, 2014.

Oskamp, S. 1982. Overconfidence in case-study judgments. In D. Kahneman, P. Slovic, \& A. Tversky (Eds.), Judgments under uncertainty heuristic and biases: 287-293. Cambridge, UK: Cambridge University Press.

Papadakis, V. M., Lioukas, S., \& Chambers, D. 1998. Strategic decision-making processes: The role of management and context. Strategic Management Journal, 19: 115-147.

Pearce, J., \& Zahra, S. 1992. Board composition from a strategic contingency perspective. Journal of Management Studies, 29: 411-438.

Pfeffer, J. 1972. Size and composition of corporate boards of directors: The organization and its environment. Administrative Science Quarterly, 17: 218-228.

Pfeffer, J. 1973. Size, composition and function of hospital boards of directors: A study of organizationenvironment linkage. Administrative Science Quarterly, 18: 349-364.

Platt, H., \& Platt, M. 2012. Corporate board attributes and bankruptcy. Journal of Business Research, 65: 1139-1143.

Pontikes, E., Negro, G., \& Rao, H. 2010. Stained red: A study of stigma by association to blacklisted artists during the "Red Scare" in Hollywood, 1945 to 1960. American Sociological Review, 75: 456-478.

Porter, M. E. 1991. Towards a dynamic theory of strategy. Strategic Management Journal, 12: 95-117.

PricewaterhouseCoopers 2014. Trends shaping governance and the board of the future. Available from http://www.pwc.com/us/en/corporate-governance/ annual-corporate-directors-survey/assets/annualcorporate-directors-survey-full-report-pwc.pdf, accessed June 1, 2015.

Robins, J. M., Hernán, M. A., \& Brumback, B. 2000. Marginal structural models and causal inference in epidemiology. Epidemiology (Cambridge, Mass.), 11: 550-560.

Rosenstein, S., \& Wyatt, J. G. 1990. Outside directors, board independence, and shareholder wealth. Journal of Financial Economics, 26: 175-191.

Ruef, M., \& Scott, W. R. 1998. A multidimensional model of organizational legitimacy: Hospital survival in changing institutional environments. Administrative Science Quarterly, 43: 877-904.

Russo, J. E., \& Schoemaker, P. J. 1992. Managing overconfidence. Sloan Management Review, 33: 7-17.

Seballos, L. D., \& Thomson, J. B. 1990. Underlying causes of commercial bank failures in the 1980s. Economic Commentary. Available from https://www.clevelandfed.org/ 
research/ commentary/1990/0901.pdf, accessed July 19, 2014.

Shapira, Z. 1995. Risk taking: A managerial perspective. New York, NY: Russell Sage Foundation.

Shlyakhter, A. I., Kammen, D. M., Broido, C. L., \& Wilson, R. 1994. Quantifying the credibility of energy projections from trends in past data-The United States energy sector. Energy Policy, 22: 119-130.

Simon, M., \& Houghton, S. M. 2003. The relationship between overconfidence and the introduction of risky products: Evidence from a field study. Academy of Management Journal, 46: 139-149.

Sniezek, J. A., \& Henry, R. A. 1989. Accuracy and confidence in group judgment. Organizational Behavior and Human Decision Processes, 43: 1-28.

Stiles, P. 2013. Board committees. In M. Wright, D. S Siegel, \& I. Filatotchev (Eds.), The Oxford handbook of corporate governance: 177-199. Oxford, UK: Oxford University Press.

Stinchcombe, L. 1965. Social structure and organizations. In J. G. March (Ed.), Handbook of organizations: 260-290. Chicago, IL: Rand McNally.

Tilcsik, A. 2010. From ritual to reality: Demography, ideology, and decoupling in a post-Communist government agency. Academy of Management Journal, 53: 1474-1498.

Tiwana, A., Wang, J., Keil, M., \& Ahluwalia, P. 2007. The bounded rationality bias in managerial valuation of real options: Theory and evidence from IT projects. Decision Sciences, 38: 157-181.

Ungar, S. 2008. Ignorance as an under-identified social problem. The British Journal of Sociology, 59: 301-326.

United States General Accounting Office 1991. Failed banks: Accounting and auditing reforms urgently needed. United States General Accounting Office, AFMD-91-43. http:// www.gao.gov/assets/160/150382.pdf, accessed June 1, 2015.

Van Der Vegt, G. S., \& Bunderson, J. S. 2005. Learning and performance in multidisciplinary teams: The importance of collective team identification. Academy of Management Journal, 48: 532-547.

Van Knippenberg, D., \& Schippers, M. C. 2007. Work group diversity. Annual Review of Psychology, 58: 515-541.

Wang, C. S., \& Thompson, L. L. 2006. The negative and positive psychology of leadership and group research. Advances in Group Processes, 23: 31-61.

Westphal, J. D. 1999. Collaboration in the boardroom: Behavioral and performance consequences of CEOboard social ties. Academy of Management Journal, 42: 7-24.

Westphal, J. D., \& Milton, L. P. 2000. How experience and network ties affect the influence of demographic minorities on corporate boards. Administrative Science Quarterly, 45: 366-398.

Williams, K. Y., \& O’Reilly, C. A. 1998. Demography and diversity in organizations. Research in Organizational Behavior, 20: 77-140.

Winship, C., \& Morgan, S. L. 1999. The estimation of causal effects from observational data. Annual Review of Sociology, 25: 659-706.

Woolley, A. W., Gerbasi, M. E., Chabris, C. F., Kosslyn, S. M., \& Hackman, J. R. 2008. Bringing in the experts: How team composition and collaborative planning jointly shape analytic effectiveness. Small Group Research, 39: 352-371.

Yue, L., Luo, J., \& Ingram, P. 2013. The failure of private regulation: Elite control and market crises in the Manhattan banking industry. Administrative Science Quarterly, 58: 37-68.

Zald, M. N., \& Lounsbury, M. 2010. The wizards of Oz: Towards an institutional approach to elites, expertise and command posts. Organization Studies, 31: 963-996.

Zhu, D. H. 2013. Group polarization on corporate boards: Theory and evidence on board decisions about acquisition premiums. Strategic Management Journal, 34: 800-822.

\section{$M$}

Juan Almandoz (jalmandoz@iese.edu) is an assistant professor of managing people in organizations at IESE Business School. He received his $\mathrm{PhD}$ in organizational behavior from Harvard University. His research focuses on organizational theory, top management teams, and the governance of organizations with economic and social missions.

András Tilcsik (andras.tilcsik@rotman.utoronto.ca) is an assistant professor of strategic management at the Rotman School of Management, University of Toronto. He received his $\mathrm{PhD}$ in organizational behavior from Harvard University. His research focuses on organizations, occupations, and work.

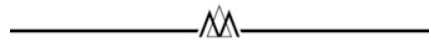

\section{APPENDIX A}

\section{EXPLORATORY INTERVIEWS IN THE CONTEXT OF LOCAL BANKS}

\section{Data Collection}

As part of a broader research program carried out between 2008 and 2013 (see Almandoz, 2012, 2014), one of 
the authors interviewed 77 informants deeply familiar with local banks in the United States: members and chairmen of local banks' boards $(n=21)$, current and prospective bank CEOs $(n=42)$, bank employees $(n=10)$, and individuals planning to start a bank $(n=4)$. Interview targets were selected randomly from the list of banks included in our statistical analysis, and participants provided additional referrals. Conducted by phone or in person, most interviews lasted between 30 and 60 minutes. The interviews followed a semi-structured protocol and were audiotaped and transcribed. In interviews with directors and CEOs, the questions "How well has the board performed?" and "What do bankers and non-bankers bring to the board?" proved to be particularly relevant to our topic.

\section{Data Analysis}

To examine the interview data, we coded interview notes inductively for observations that were pertinent to the composition of boards. Our initial codes were "in vivo" codes. We then reviewed these labels and grouped them into more abstract categories, moving from respondents' particular observations (e.g., "people that aren't bankers tend to be more cautious") to codes (e.g., "non-bankers' cautiousness"), which we then sorted under broader categories (e.g., "nonbankers characteristics"). We then identified themes that occurred most frequently in our respondents' accounts. To further facilitate the detection of patterns, we also employed matrices (Miles \& Huberman, 1994). A role-ordered matrix was especially helpful because it helped us detect differences in the effect of domain experts and non-experts (see Tilcsik, 2010). In this display, each matrix row represented one professional background, while the two columns contained our informants' observations about the (a) beneficial and (b) detrimental effects of directors from a particular professional background. We populated the matrix by identifying the instances when the relevant combination of observations occurred for each cell (e.g., "directors with a real estate background - detrimental effects”). This matrix helped reveal themes about different professional backgrounds that were most salient to our interviewees. 


\section{APPENDIX B}

TABLE B1

First-Stage Probit Model Predicting the Likelihood of a Board Having a Proportion of Bankers above the Median Level ${ }^{a}$

\begin{tabular}{lc}
\hline & Model B1 \\
\hline De novo bank & $-.40^{* *}$ \\
& $(.09)$ \\
Number of banks in county & $.004^{* *}$ \\
& $(.001)$ \\
Charter approval received from Office & $.19^{*}$ \\
of the Comptroller of the Currency & $(.09)$ \\
GDP growth & $.05^{*}$ \\
& $(.02)$ \\
Board with a chair-CEO & $.31^{* *}$ \\
& $(.08)$ \\
Intercept & -.09 \\
& $(.11)$ \\
Log likelihood & -901.0 \\
Likelihood ratio $\chi^{2}(d f=5)$ & 59.73 \\
\hline
\end{tabular}

${ }^{\text {a }} n=1,307$ banks. Robust standard errors are in parentheses.

${ }^{*} p<.05$

$* * p<.01$ 


\section{APPENDIX C}

TABLE C1

Regression Models with Alternative Financial Distress Indicators ${ }^{\mathrm{a}}$

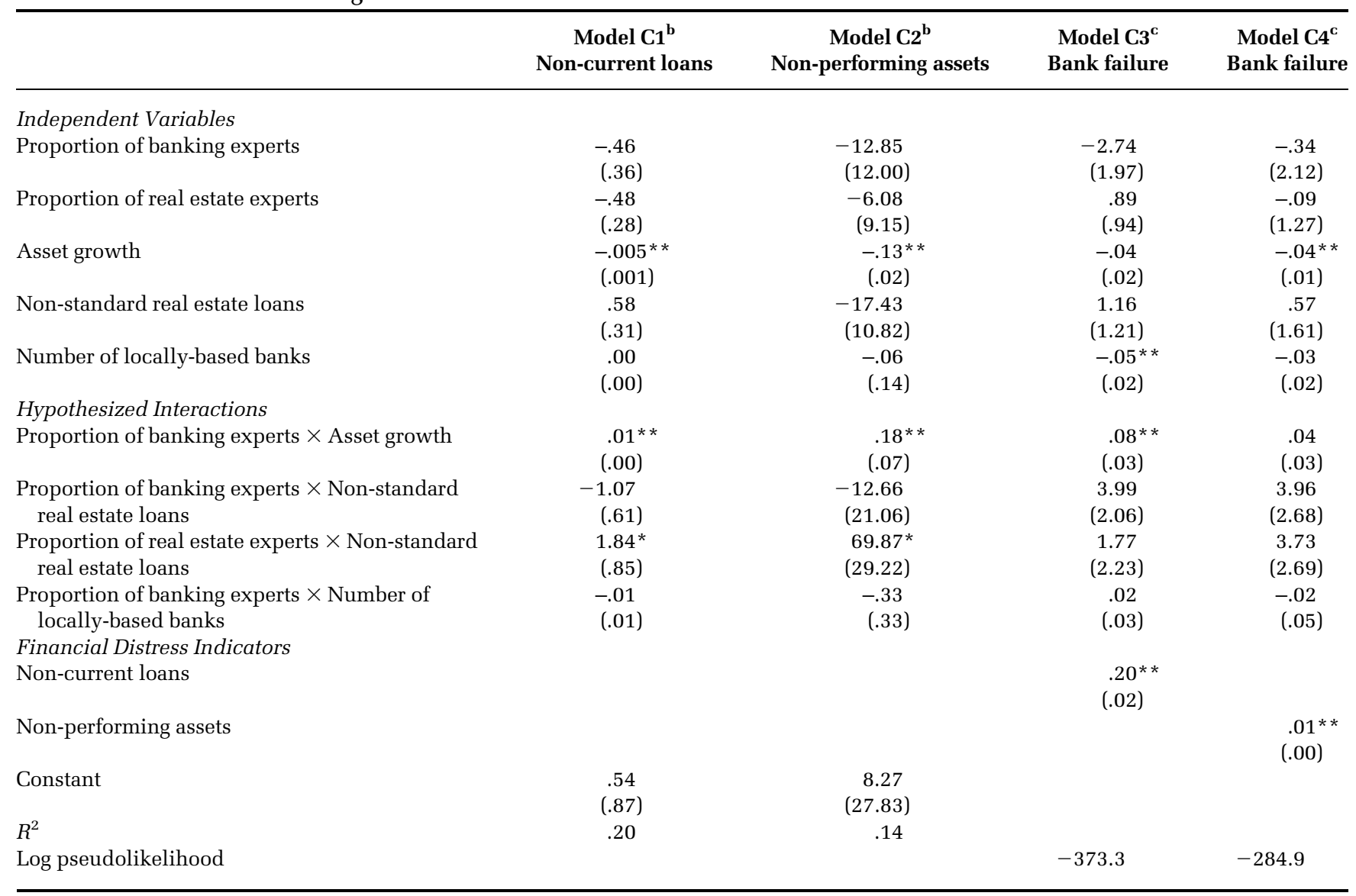

${ }^{\text {a }} n=9,957$ bank-years (1,307 banks). All models include the control variables from Table 2. Robust standard errors, adjusted for clustering by bank ID, are in parentheses.

${ }^{\mathrm{b}}$ Random effects regression models.

${ }^{\mathrm{c}}$ Competing-risks regression models.

${ }^{*} p<.05$

${ }^{* *} p<.01$ 
Copyright of Academy of Management Journal is the property of Academy of Management and its content may not be copied or emailed to multiple sites or posted to a listserv without the copyright holder's express written permission. However, users may print, download, or email articles for individual use. 